\title{
Seasonal versus Episodic Performance Evaluation for an Eulerian Photochemical Air Quality Model
}

Ling Jin, Nancy J Brown

Lawrence Berkeley National Laboratory, Berkeley, CA 94720

Robert A Harley

University of California, Berkeley, CA 94720

Jian-Wen Bao, Sara A Michelson, James M Wilczak

National Oceanographic and Atmospheric Administration, Boulder, CO 80305

Corresponding author: Nancy J Brown, njbrown@lbl.gov, 510-486-4241

\begin{abstract}
This study presents detailed evaluation of the seasonal and episodic performance of the Community Multiscale Air Quality (CMAQ) modeling system applied to simulate air quality at a fine grid spacing (4 km horizontal resolution) in central California, where ozone air pollution problems are severe. A rich aerometric data base collected during the summer 2000 Central California Ozone Study (CCOS) is used to prepare model inputs and to evaluate meteorological simulations and chemical outputs. We examine both temporal and spatial behaviors of ozone predictions. We highlight synoptically-driven high-ozone events (exemplified by the four Intensive Operating Periods, IOPs) for evaluating both meteorological inputs and chemical out puts (ozone and its precursors) and compare them to the summer average. For most of the summer days, cross-domain normalized gross errors are less than $25 \%$ for modeled hourly ozone, and normalized biases are between $\pm 15 \%$ for both hourly and peak ( $1 \mathrm{~h}$ and $8 \mathrm{~h}$ ) ozone. The domain-wide aggregated metrics indicate similar performance between the IOPs and the whole summer with respect to predicted ozone and its precursors. Episode-to-episode differences in ozone predictions are more pronounced at a subregional level. The model performs consistently better in the San Joaquin Valley than other air basins, and episodic ozone predictions there are similar to the summer average. Poorer model performance (normalized peak ozone biases $<-15 \%$ or $>15 \%$ ) is found in the Sacramento Valley and the Bay Area and is most noticeable in episodes that are subject to the largest uncertainties in meteorological fields (wind directions in the Sacramento Valley and timing and strength of onshore flow in the Bay Area) within the boundary layer.
\end{abstract}


Keywords: Model evaluation; air quality modeling, central California; ozone; CMAQ

\section{Introduction}

Ozone is designated as a criteria pollutant because of its adverse effects on human health (Lippmann 1989, 1993; Bell et al. 2004; Bell and Dominici 2008) and on agricultural productivity (see review by Emberson et al. 2009). Ozone also affects global climate, because ozone is a greenhouse gas (IPCC 2007), and ozone photolysis in the presence of water vapor forms hydroxyl radicals which, in turn, affect the lifetimes of other important greenhouse gases such as methane (Stevenson et al. 2000).

Understanding and controlling troposphere ozone is challenging because it is a secondary pollutant, formed in the presence of sunlight by chemical reactions involving precursor emissions of volatile organic compounds (VOC), carbon monoxide (CO), and nitrogen oxides $\left(\mathrm{NO}_{\mathrm{x}}\right)$. Ozone control strategy design efforts (e.g. State Implementation Plans; SIPs) rely on photochemical air quality models to explore how emission reduction strategies might mitigate elevated $\mathrm{O}_{3}$ concentrations at local and regional scales. Such simulations are usually conducted for a few short ( 3 to 5 days) high-ozone episodes, driven by a representative emission inventory and meteorological fields (Winner and Cass 2000). Sometimes models used in SIP preparation are tuned to optimize base case performance by adjusting input data and model parameters for specific episodic conditions. Episodes for which model performance is unsatisfactory are typically discarded from control strategy design efforts. The variability of the real atmosphere and ozone responses to precursor emissions are not captured fully in episodic modeling. Modeling air quality over longer periods may help to improve the understanding of ozone responses to emissions for a range of different weather conditions. Besides regulatory practices, longer-term simulations are also more relevant to measure ozone adverse effects on crops and forests over a full growing season, and to anticipate changes in atmospheric composition under future climate (e.g. Hogrefe et al. 2004b; Liao et al. 2006; Tao et al. 2007; Nolte et al. 2008). 
The Community Multiscale Air Quality Model (CMAQ) (Byun and Schere 2006) is widely used to study air pollutant formation and transport. Model performance for specific geographic regions is mostly evaluated for short episodes (e.g. Mebust et al. 2003; Zhang et al. 2005; Zhang et al. 2006), and studies often focus on multi-state regions in the eastern US. While longer-term simulations are desirable, fewer studies are conducted mainly due to lack of adequate supporting data for model input preparation and performance evaluation, as well as high computational cost. Hogrefe et al. (2001; 2004a; 2006) evaluated CMAQ's ability to capture summer ozone variability observed in present-day climate over the eastern US, focusing on the temporal features of the distributions. Eder et al. evaluated a forecast model with pair-wise comparisons between simulated ozone and extensive ground measurements over a summer season for the eastern US domain (2006) and the whole continental US (2009). Similar pair-wise comparison was conducted by Tong and Mauzerall (2006) for the whole continental US to evaluate predicted ozone spatial variability over one summer month. These longerterm simulations and performance evaluations generally relied on routine emission inventories and measurement networks, ozone precursor predictions were often not addressed. The coarser horizontal resolution (e.g. $36 \mathrm{~km}$ used in Tong and Mauzerall 2006 and $12 \mathrm{~km}$ used in Eder et al. 2009) may affect the model's ability to represent variable terrain and land use in the mountainous west. The central California region has long been suffered from server ozone problems (Jin et al. 2008) and understanding CMAQ performance here is critical for model application.

The meteorology inputs are an integral part of photochemical modeling. Uncertainties in these inputs affect not only the simulated ozone levels, but also ozone responses to emission changes (Biswas and Rao 2001; Jin et al. 2008). Ideally, meteorology simulations can be evaluated in conjunction with chemical predictions to interpret episode-to-episode and region-to-region differences in model performance. However, such efforts can only be supported when sufficient data are available and therefore are commonly not pursued together with chemical evaluations.

In this study, we seek a more comprehensive model evaluation by applying MM5CMAQ (version 4.5 is used despite the later release of versions 4.6 and 4.7 ) to the entire summer of 2000 in central California, where significant spatial and temporal variations in 
air quality are observed. A fine grid spacing $(4 \mathrm{~km})$ is used to account for the complex terrain of the study domain. A rich aerometric data base collected during the summer 2000 Central California Ozone Study (CCOS) including ozone and its precursor species. Emission inputs are developed under the CCOS period to describe variability occurring on diurnal, weekly, and seasonal time scales. Furthermore, a network of 25 wind profilers was deployed to collect information on the winds and temperature structure in the lower troposphere in the Central Valley to improve the understanding of meteorology in this region. These data can be used to assess the impact of uncertainties in meteorological fields on chemical outputs. In addition to assessing temporal and spatial behaviors of ozone predictions, this paper focuses on similarity and differences in seasonal and episodic performance of the meteorological and chemical simulations. Both ozone and its precursor predictions are evaluated in conjunction to assessment of MM5 modeled meteorological fields. Evaluation metrics are presented for the full summer season and for four short intensive operating periods (IOPs) during CCOS that represent distinct meteorological conditions where high ozone concentrations were observed.

\section{Data and methods}

\subsection{Study domain}

The CCOS domain shown in Figure 1 extends from approximately 34 to $41^{\circ} \mathrm{N}$ and 116 to $124^{\circ} \mathrm{W}$, is modeled using a $185 \times 185$ grid with a horizontal resolution of $4 \mathrm{~km}$. Vertically, the domain is divided into 27 layers from the surface to $100 \mathrm{mb}$ (about 17 $\mathrm{km}$ ); the near-surface layers are about $20 \mathrm{~m}$ thick. Air basins in the study domain include the San Joaquin Valley (SJV), San Francisco Bay Area (SFB), Sacramento Valley (SV), Mountain Counties (MC), as well as several others as shown in Figure 1.

The inner domain (SARMAP domain 96×117 grid cells) includes the entire SJV and $\mathrm{SFB}$, as well as the Sacramento metropolitan area that contains most of the emissions from the SV. The smaller domain has been used for more detailed mechanistic and diagnostic evaluations conducted over shorter time periods.

\subsection{Preliminary mechanistic and diagnostic evaluations}

Model simulations were first conducted for the smaller SARMAP domain and a 15day period (24 July to 8 August 2000) that includes some of the highest-ozone days. 
Information from these simulations provided guidance on model application and performance issues for simulating the entire summer season using the larger CCOS domain. Results of the mechanistic and diagnostic evaluation on the SARMAP domain are reported elsewhere (Harley et al. 2006; Jin et al. 2007; Jin et al. 2008). Diagnostic simulations are summarized in Table 1.

Parameters considered in diagnostic simulations 1 to 4 mostly affected predictions in coastal areas and/or nighttime ozone concentrations. Ozone boundary conditions are especially important for correctly simulating ozone concentrations along the coast, but have significantly less effect on inland areas. The model was found to overestimate ozone concentrations at night at many locations. Urban observation sites appear to be influenced by nocturnal emissions of $\mathrm{NO}_{\mathrm{x}}$. The overprediction of ozone might, in some cases, result from ozone titration by fresh $\mathrm{NO}_{\mathrm{x}}$ emissions; this sub-grid variability can not be resolved with $4 \mathrm{~km} \times 4 \mathrm{~km}$ grid cells. Odd oxygen $\left(\mathrm{NO}_{2}+\mathrm{O}_{3}\right)$ provides a more robust basis for model evaluation at night and should be more accurately predicted by the model (see Figure S1 in the Supporting Information). As a result, later evaluations of predicted ozone and nitrogen species will focus on daytime values.

Assimilation of radar wind profiler and other observed meteorological data in the MM5 model considerably improves air quality model performance for ozone in the Bay Area and Sacramento Valley on certain days (normalized biases reduced by about factor of two), but overall performance for the entire domain is similar to the un-nudged case.

Some model input parameters were refined according to results of the diagnostic simulations, field measurements, and literature review. Ozone dry deposition velocity over the ocean is increased from the default value of zero to the measured values of 0.04 $\mathrm{cm} / \mathrm{s}$ (Faloona, 2006, personal communication). The default minimum eddy diffusivity in CMAQ $\left(\mathrm{K}_{z \min }=0.5 \mathrm{~m}^{2} / \mathrm{s}\right)$ is too high for stable marine layers on the western boundary, and this causes excessive vertical mixing that leads to increases in surface ozone. $\mathrm{K}_{\mathrm{zmin}}$ was set to a lower value of $0.1 \mathrm{~m}^{2} / \mathrm{s}$. Temporally constant pollutant concentrations are specified for each of the four lateral boundaries of the domain, with the western boundary treated differently from the others (see Jin et al. 2008): vertically-varying ozone concentrations were specified for the western boundary based on ozone-sonde observations at Trinidad Head, CA (Harley et al. 2006). These changes to model 
parameters were made and held fixed while simulating the whole summer season for the larger CCOS domain.

\subsection{Emission inputs}

Emission inputs have been considered as a major source of uncertainty in AQ modeling (Russell 2000). For longterm modeling, it is important to assign adequate variability to the emission inputs, to drive the variability in model outputs. Emission inventory files were provided by the California Air Resources Board (CARB) developed under the CCOS period in five source categories: area sources, motor vehicle, point sources, biogenic, and forest fires. The anthropogenic emissions are estimated with data collected during a one-week intensive operating period. Off-road mobile sources were inventoried and included with area sources. Figures 2 and 3 describe the variability in emission inputs specified for the summer period with more detailed description as follows.

Anthropogenic emissions (area, mobile, and point sources) are specified with day of week differences (Figure 2) and the same weekly cycle was repeated for the whole summer. Area source $\mathrm{NO}_{\mathrm{x}}$ emissions are generally lower ( $\sim 16 \%$ domain wide) on weekends, but volatile organic compound (VOC) emissions are estimated to be higher ( $\sim 19 \%$ domain wide) on weekends because of increased recreational activities (e.g. boating). For motor vehicle emissions, relative to weekdays, there are large reductions in diesel truck traffic and associated $\mathrm{NO}_{\mathrm{x}}$ emissions on weekends. On average, weekend mobile $\mathrm{NO}_{\mathrm{x}}$ emissions are about 25 percent less than those on weekdays, while reductions in on-road mobile VOC emissions are less than 10 percent. Individual point sources are described by location, stack parameters (diameter, height, exit temperature, exit velocity), and hourly emissions of pollutants. Plume rise is estimated for each point source using the emission preprocessor SMOKE version 2.1 (Coats 1995) driven by dayspecific MM5 meteorology.

Hourly biogenic emissions (mainly isoprene and terpenes) were estimated for each individual day of the summer season. Emissions were estimated using the BEIGIS modeling system (Scott and Benjamin 2003) by applying date-specific temperatures and sunlight intensity to seasonally adjusted leaf-cover estimates. Daily emissions in metric 
tons are shown in Figure 3 for isoprene and terpenes. Isoprene emissions occur only in the presence of light, and increase with solar radiation until a saturation point is reached. The emissions increase exponentially with temperature up to approximately $35-40^{\circ} \mathrm{C}$, after which they decrease. Monoterpene emissions increase exponentially with temperature and are not dependent on light. These light and temperature effects are represented in the model using parameterizations (Guenther et al. 1995). Total biogenic emissions vary on a daily basis from 500 tons to as much as 3500 tons, depending on meteorology. Biogenic emissions are especially prevalent in the foothills of the Sierra Nevada and the coastal mountain ranges, and are generally not collocated with large anthropogenic emission fluxes.

\subsection{Meteorological fields}

The National Center for Atmospheric Research/The Pennsylvania State University Mesoscale Model (MM5) (Grell et al. 1994) version 3 was used to perform a series of 5day simulations (except for two 3-day periods at the beginning and end of the time period) starting at 1200 UTC 1 June to 1200 UTC 30 September 2000 and centered around the 5-day Intensive Observation Period (IOP) that began on 29 July 2000, which is the same as used in Michelson et al. (2009). The simulations for the whole summer period were carried out without data assimilation. A set of 36-12-4 km one-way nested grids that have 50 vertical stretched levels was used, 30 of which are within the lowest 2 $\mathrm{km}$. The lowest model level is at about 12 meters above the surface. The boundary and initial conditions were prescribed using the six-hourly $40 \mathrm{~km}$ National Centers for Environmental Prediction (NCEP) Eta analyses. All of the simulations used the Eta Atmospheric boundary layer scheme (Janjic 2002). The Dudhia simple microphysics parameterization was used along with the Dudhia short-wave and Rapid Radiation Transfer Model (RRTM) long-wave radiation parameterization schemes. The 36- and 12-km grids used the Grell convective parameterization scheme (Grell, 1993), while no convective parameterization scheme was used on the 4-km grid. Details of all the physics options are available in Grell et al. (1994).

Meteorological fields with $4 \mathrm{~km}$ resolution were used as input for air quality modeling in this study. The Meteorology to Chemistry Interface Processor (MCIP version 
3.3) was used to construct CMAQ model-ready input files from the MM5 output, and it allows for consolidation of vertical layers. We used 27 layers for CMAQ from the original 50 MM5 layers without changing the first $200 \mathrm{~m}$ (9 layers) to preserve high resolution near the ground. To avoid potential influences of boundary grid cells, the origin of the meteorological domain was shifted inside by 2 grids, and a subset of the full 190×190 MM5 $4 \mathrm{~km}$ domain was used for driving air quality simulations.

\subsection{Intensive operating periods (IOPs)}

The typical synoptic scale meteorological features favoring ozone formation and accumulation in central California are strong high pressure systems built over the eastern Pacific (Eastern Pacific High) or the Four Corners (Western US High). The high pressure system is manifest as a dome of warm air (a maximum in the 500-mb geopotential height field) with a surrounding anticyclonic circulation (clockwise in the Northern Hemisphere). The sinking motion of air aloft is associated with fair weather and gives rise to adiabatic heating and warm temperatures. An off-shore pressure gradient caused by the high-pressure system reduces incoming westerly flow at the coast and creates stagnant conditions in the San Joaquin Valley. A less typical weather associated with high ozone levels is monsoonal flow: an upper-level high is centered in the south-western U.S. or in northern Mexico such that southerly flow transports moisture north. The atmosphere is less stable in this case, but often results in ozone exceedances in the SJV.

Several intensive operating periods (IOPs) were identified during CCOS; each one is associated with one of the above synoptic patterns. High ozone concentrations were observed during all of these IOPs. Detailed descriptions can be found in Fujita et al. (2001). We extend shorter IOPs ( 1 or 2 days) to 3 days to facilitate the analysis.

1) Jul 23-25 (day 205-207): Monsoonal Flow

2) Jul 29-Aug 2 (day 211-215): Western US High

3) Aug 14-17 (day 227-230): Western US High

4) Sept 17-20 (day 261-264): Eastern Pacific High

\section{Air quality model simulations and performance evaluation}


CMAQ version 4.5 was configured to use the piecewise parabolic method for advection, horizontal diffusion, and vertical diffusion, and the Euler Backward Iterative (EBI) ordinary differential equation solver for chemistry. Gas-phase chemistry is represented using the SAPRC99 chemical mechanism (Carter 2000).

\subsection{Simulated ozone concentrations}

Simulated $8 \mathrm{~h}$ ozone maxima averaged over the whole summer and for individual IOPs are shown in Figure 4, with ozone levels greater than $84 \mathrm{ppb}$ marked in the darker shade of orange that are referred to as "high ozone". During the summer, on average, high ozone levels occur downwind of Fresno and Bakersfield. Four IOPs each showed distinct ozone spatial patterns. Coastal areas and the SFB in IOP1 were relatively clean, while high ozone was found in the Mountain counties and eastern side of the SJV. IOP2 exhibited the highest domain-wide ozone levels among all the IOPs with elevated ozone in Sacramento, both sides of the SJV, and near the coastal mountain ranges. Elevated ozone levels in IOP3 were mostly seen in the SJV; in IOP4, high ozone levels were seen in the SFB and downwind coastal areas, as well as in the SJV and the Mountain counties. In all cases, ozone levels in the SJV were high.

Hourly ozone concentrations were measured at 149 ground stations located throughout the CCOS domain. At individual sites, modeled ozone time series followed the observed temporal patterns (see time series plots in Figure S2 in the Supporting Information). The model is able to capture both high- and lower-ozone days. Nighttime ozone levels were often over-predicted, a problem that has been encountered in other modeling studies (e.g. Eder 2006). The nighttime discrepancies are partly due to the titration of $\mathrm{O}_{3}$ with fresh $\mathrm{NO}_{x}$ emissions. Additionally, nighttime ozone levels are more

prone to the uncertainties in vertical mixing as we discussed in our preliminary diagnostic simulations (Table 1). Hence, our evaluation of ozone focuses on daily $1 \mathrm{~h}$ and $8 \mathrm{~h}$ maxima, and when comparing hourly ozone levels, a cutoff value of $60 \mathrm{ppb}$ will be used so as to focus on daytime ozone when vertical mixing is more vigorous. Since nighttime concentrations will be affected by titration effects, model predicted total nitrogen species $\left(\mathrm{NO}_{\mathrm{y}}\right)$ will only be compared to observations during the better-mixed daytime hours (10 $\mathrm{AM} \sim 5 \mathrm{PM}$ when the PBL height remains high). 


\subsection{Temporal and spatial behaviors of ozone predictions}

To investigate ozone model performance further, daily normalized biases and gross errors were calculated (Figure 5ab) using the hours and sites where observed ozone levels are greater than $60 \mathrm{ppb}$. The normalized biases are largely within $\pm 15 \%$ throughout the whole summer period with only a few exceptions. The normalized gross errors are mostly less than $25 \%$ and only one day is more than $35 \%$.

Daily average station peak prediction accuracy ${ }^{1}$ is calculated for $1 \mathrm{~h}$ and $8 \mathrm{~h}$ average peak ozone (Figure 5c). Observed peak ozone is determined as the maximum value in the time interval from $10 \mathrm{AM}$ to $8 \mathrm{PM}$ without more than 3 missing values. Peak prediction accuracy was measured with strict pairing in space and time.

The model generally underpredicts peak ozone (for observed peak $>60 \mathrm{ppb}$ ), especially for the $1 \mathrm{~h}$ peak. Figure $5 \mathrm{~d}$ shows observed daily average peak ozone. One can see that the model underpredicts peak ozone on both high and low ozone days.

To evaluate the spatial behavior in model predictions, ozone performance statistics are aggregated over the whole domain and for selected air basins where high ozone levels are observed, namely in the SJV, SV, SFB, and MC (Table 2). Despite the spatial differences, across all the air basins, the summer average metrics for ozone (hourly or peak) only showed modest underprediction within $10 \%$ and normalized gross errors around $20 \%$. These statistics are better than the ones found previous studies over California (Tong and Mauzerall 2006; Eder et al. 2009) conducted with coarser horizontal resolutions. Ozone predictions in the SJV compare better with observations than for the CCOS domain as a whole, while the SFB generally has less satisfactory performance than other sub-regions. Initial model diagnostics showed that the SFB is highly sensitive to uncertainties in both anthropogenic and biogenic emission sources, boundary conditions, sea breeze strength and timing, and light attenuation by coastal stratus, which together pose significant challenges for simulating ozone concentrations.

Averaged over the entire summer, the model under-predicts ozone, including hourly values, as well as $1 \mathrm{~h}$ and $8 \mathrm{~h}$ peak ozone, in all sub-regions we examined, for cases with

\footnotetext{
${ }^{1}$ Defined by EPA model evaluation guidance (1991), equivalent to peak ozone biases averaged over all the measurement stations in the domain.
} 
observed ozone levels greater than $60 \mathrm{ppb}$. Strict pairing in time and space can be unrealistic given the uncertainties in the input data and model processes. Part of the problem with $1 \mathrm{~h}$ peak values may be a mismatch in timing of modeled versus observed peak ozone. When the comparison of simulated peak values is relaxed to be within a $3 \mathrm{~h}$ window centered on the observed peak hour, the average bias of $1 \mathrm{~h}$ peak ozone changed from negative to positive across all the air basins and (normalized) gross errors were reduced or remained unchanged except for the SJV where the gross error increased slightly but is still within $25 \%$. According to the distributions of hourly ozone peak time (Figure S3), only $8 \%$ of the modeled peaks occur after 4 PM, compared to $23 \%$ of the observed peaks. Ozone tends to decrease during the transition hours (5-7 PM) before sunset due to reduced photolysis rates. Further inspection of diurnal ozone profiles indicates this decreasing trend occurs earlier and/or is steeper in the model than in the observations. This may suggest that the modeled photolysis rates are too low in these hours. The meteorological evaluation in the next section suggests that the transition hours are subject to more uncertainties in predicted boundary layer heights and wind fields, which may also affect simulated ozone concentrations. Predicted $8 \mathrm{~h}$ average peak ozone compares better with observed values than the $1 \mathrm{~h}$ peak concentrations.

Relaxing the spatial pairing of modeled ozone to be within $\pm 1,3$, or 5 grid cell(s) of the observation site generally does not improve model performance statistics for either 1 $\mathrm{h}$ or $8 \mathrm{~h}$ peak values. Subgrid differences in pairing are not investigated here, however, it has been found that the incommensurability between model volume-averages and the pointwise observations may contribute to poorer performance statistics when ozone spatial correlation assumes sharper decreases for short distances (Swall and Foley 2009). Detailed comparisons can be found in the Supporting Information (Tables S1 to S4).

Performance statistics are sensitive to the choice of cutoff concentration, the value below which observations are excluded in evaluating model performance. When the cutoff concentration for ozone is reduced from 60 to $40 \mathrm{ppb}$, the biases become positive: $\sim 2 \mathrm{ppb}$ for hourly ozone, and 2-6 ppb for $8 \mathrm{~h}$ peak ozone, across all sub-regions. Comparison with the complete range of observed $8 \mathrm{~h}$ peak ozone is shown in Figure S4 The model tends to over predict ozone in the lower range $(<60 \mathrm{ppb})$, which is similar to findings from other studies (Tong and Mauzerall 2006; Eder et al. 2006). The model 
predicts more accurately in the 60 to $80 \mathrm{ppb}$ range while other studies found the best prediction range is in lower concentrations ( $40 \sim 50 \mathrm{ppb}$ in Tong and Mauzerall 2006, and 50 70 ppb in Eder et al. 2009). Eder et al. (2006) attributed over-predictions of the smaller values of observed $8 \mathrm{~h}$ peak ozone to days with non-conducive meteorological conditions that have more cloud cover and/or precipitation. In central California, summer time is characterized by clear skies and low humidity. Only in the coastal regions where ozone levels are consistently low (see the time series plot in Figure S2 as an example), do we observe ozone over-predictions throughout the summer. Spatial distributions of normalized biases at individual grid cells are examined in the next section.

\subsection{Model performance for different synoptic events}

To identify common and distinctive features in model performance under different meteorological conditions, we evaluate both meteorological and chemical simulations across synoptic events (exemplified by the four IOPs) and compare them with average model performance for the whole summer.

\subsubsection{Evaluation of meteorological parameters}

The meteorological fields simulated by MM5 are evaluated by dividing the Central Valley (consisting of Sacramento Valley and San Joaquin Valley) into 3 areas: the (middle) Sacramento Valley (SV), the central part, and the (middle-southern) San Joaquin Valley (SJV). Three areal clusters of profiler locations are used to evaluate the model performance in each of these regions. These clusters are referred to as the Sacramento cluster, the Central cluster and the Fresno cluster, respectively (see Figure 6). The wind-profiler sites that are included in the averaging in the Sacramento cluster are: Chico (CCO), Arbukle (ABK) and Pleasant Grove (PSG). The profiler sites included in the Central cluster are: Travis (TRA), Livermore (LVR), Los Banos (LBA), Waterford (WFD), Tracy (TCY) and Sacramento (SAC). The profiler sites included in the Fresno cluster are: Fresno (FAT), Lemoore (LEM), Lost Hills (LHS), Angiola (AGO), Bakersfield (BKF) and Visalia (SJV). The wind profilers provide hourly averages of wind speed and direction, typically to heights of $3000 \mathrm{~m} \mathrm{AGL}$, and virtual temperature up to about 1000 m AGL determined using the Radio Acoustic Sounding System technique. 
The information collected by the wind profilers can also be used to determine the depth of the daytime convective atmospheric boundary layer (ABL) by visually inspecting values of range-corrected signal-to-noise ratio, vertical velocity, which is large within the convective boundary layer, and radar spectral width, which is a measure of turbulence intensity. Meteorological parameters examined here are wind speed and direction, ABL depth, and surface temperature.

Figure 7 shows a time height series of the diurnal cycle of MM5-simulated and profiler-derived winds averaged over the entire summertime period in the three areal clusters (Sacramento, Central and Fresno clusters). The Sacramento cluster characterizes meteorology fields in the Sacramento Valley. The central cluster characterizes the incoming marine flows from the Bay Area to the central valley, which directly influence the transport and accumulation of pollutants in the Bay Area and its intermediate downwind regions (north central coasts, Sacramento metropolitan area, and northern San Joaquin Valley). The Fresno cluster covers the middle to southern parts of the San Joaquin Valley. The MM5-simulated winds in the Fresno cluster are in the best agreement with the profiler-observed winds at all levels and times. Errors in the wind direction are greatest in the Sacramento cluster. The winds within the daytime ABL are simulated well, better than any other time and any other height, in both the Central and Fresno clusters. This good agreement of the winds in the ABL indicates that the horizontal transport within the daytime ABL is simulated well in the SJV. The biggest differences in the Fresno cluster occur at night, when the low-level jet that is present between 0000 and $0800 \mathrm{UTC}$ and below about $1000 \mathrm{~m}$, is too strong in the MM5 simulations. The simulated depth of the ABL is larger than observed in all three clusters during the well-mixed hours (10 AM-5 PM). During the transition hours in the afternoon (5 PM-8 PM), the lower MM5 ABL height indicates less turbulent mixing in the model than that observed in all three clusters. Further discussion of the reasons for differences between the observed and simulated ABL is available in Michelson et al. (2009).

Similar assessment of simulated winds and ABL depth is conducted for the four IOPs (see Figures S5-8). In common with the summer average, the simulated depth of daytime ABL in individual IOPs has a positive bias except for the last IOP in September. The averaged diurnal cycle of winds in IOP4 is different from the other three IOPs and 
the summer average, because the incoming marine flow in the Central cluster and the nocturnal low-level jets in the Fresno cluster in IOP4 are much weaker than the other cases. The Sacramento cluster exhibits the poorest agreement in wind directions in ABL during IOP3 and simulated northwesterly component and the overall wind speeds are too strong during IOP4. Wind features averaged over the Central cluster characterize the incoming marine flows (indicated by the westerly component). During IOP3, the simulated marine flow is stronger than observed. During the more stagnant conditions in IOP4, the simulated marine flow is also stronger in the morning and directed more towards the south. The Fresno cluster generally has good agreement between simulated and observed winds within the daytime ABL and performance in each IOP is similar to the summer average. Temperature evaluations can be found in Michelson et al. (2009). In general, MM5 underpredicts surface temperature by about 2 to $3{ }^{\circ} \mathrm{C}$.

Wind speed and direction within the mixing layer are especially important for determining ozone transport and accumulation in particular locations. The mixing height determined from MM5 is used to calculate vertical diffusivity in CMAQ. Concentrations of primary pollutants are directly affected by both wind speed and mixing height, through advection and turbulent diffusion, and greater dilution is associated with lower concentrations. For secondary pollutants like ozone, in addition to reducing concentrations by direct transport, dilution rates can affect production rates differently and this depends on localized chemical regimes. $\mathrm{In} \mathrm{NO}_{\mathrm{x}}$ rich locations, reduced $\mathrm{NO}_{\mathrm{x}}$ concentrations will decrease titration and increase ozone concentrations. This effect may offset the direct dilution effect and lead to a net increase in ozone concentrations. We perturbed daytime (10 AM to $5 \mathrm{PM}$ ) ABL depth by $20 \%$ and verified changes in ozone can be positive or negative depending on the location (see Figure S9 in the Supporting Information). Dilution rates also affect ozone sensitivities. As elaborated in Biswas and Rao (2001), more rapid dilution of pollutants tends to shift local chemistry in polluted plumes (usually $\mathrm{NO}_{\mathrm{x}}$ rich) towards the $\mathrm{NO}_{\mathrm{x}}$ limited regime.

Uncertainties in temperature have more complicated effects on ozone chemistry ${ }^{2}$, as the rate coefficients may increase or decrease depending on the reaction (Steiner et al.

\footnotetext{
${ }^{2}$ Uncertainties in simulated temperatures here are uncoupled from emissions, which are estimated using observed temperatures.
} 
2006). Most reaction rates increase with higher temperature, however some three-body reactions proceed more slowly. A simulation with a $2{ }^{\circ} \mathrm{C}$ temperature increase was conducted and showed ozone increases in the domain with maximum changes in the regions with high anthropogenic emissions such as the Bay Area, Fresno, and Bakersfield (see Figure S10 in the Supporting Information), which is similar to the findings of Steiner et al. (2006). Ozone sensitivity to anthropogenic emissions was also evaluated with and without temperature increases, using the decoupled direct method (DDM). The most noticeable differences in ozone sensitivities were found in the Bay Area, where the largest ozone changes with temperature occur. The Bay Area is in a VOC-limited regime, and ozone sensitivity to $\mathrm{NO}_{\mathrm{x}}$ decreases with temperature while ozone sensitivity to VOC increases because more radicals are generated. In summary, a negative temperature bias generally leads to a decrease in ozone concentrations, decreased sensitivity to VOC, and increased sensitivity to $\mathrm{NO}_{\mathrm{x}}$.

\subsubsection{Evaluation of CMAQ simulations}

Evaluation metrics regarding chemical model outputs are also produced for the summer season and individual IOPs.

\subsubsection{Ozone predictions}

Pattern statistics compare variations captured in the modeled and observed data (e.g. correlations between them). Studies by Hogrefe et al. $(2001,2006)$ were focused on the model's ability to reproduce variations seen in observed fields at different time scales using a sophisticated spectrum decomposition method. Taylor (2001) has devised a very useful diagrammatic form (termed a "Taylor diagram") to visualize three simple pattern statistics: standard deviations of modeled and observed fields, $\sigma_{m}$ and $\sigma_{o}$, respectively, the root mean squared difference, $E$, and the correlation between the two fields, $R$, on the same two-dimensional plot. This method has been applied to evaluation of climate and air quality models (e.g. Vautard et al. 2007). The three metrics satisfy the Law of Cosines $\left(E^{2}=\sigma_{m}^{2}+\sigma_{o}^{2}-\sigma_{m} \sigma_{o} R\right.$ ). The Taylor diagram is shown in Figure 8 and it is plotted using a polar coordinate system. The standard deviation $\sigma_{m}$ is the radius, the correlation 
between model and observations, $R$ is the cosine of the angle. These two metrics determine the position of modeled fields (M) on the polar plot. Similarly, the position of observed fields $(\mathrm{O})$ can be determined ( $\sigma_{o}$ and angle 0 ). The root mean squared difference ( $E$ marked on Figure 8 ) is the distance between $\mathrm{M}$ and $\mathrm{O}$ (or the ideal model). The ideal model (identical to observations) is labeled on the plot to indicate the identical standard deviation, zero root mean squared difference, and perfect correlation with observed values.

We examine daytime (6 AM-9 PM) ozone patterns captured by the model in the four IOPs compared with the entire summer season (Figure 8). The whole summer season and four IOPs form a tight cluster on the Taylor diagram. This indicates that there are no large differences in model performance between the IOPs and the whole summer in terms of variability measured by the three pattern statistics. Modeled daytime ozone in all the IOPs as well as the whole summer on average tend to be less variable (as measured by standard deviation) than the observations. Correlations between the modeled and observed ozone levels are in the range of 0.6-0.7 across all time periods. All IOPs have similar root mean squared differences ( $\sim 0.75$ of the observed standard deviation) and model performance for IOP4 is slightly inferior to the other IOPs (i.e., lower correlation and larger RMS error).

Pattern statistics are useful for comparing the anomalies in two data sets, while mean bias and gross error employed earlier indicate the sign and magnitude of model prediction errors. Modeled hourly ozone, and peak ozone ( $1 \mathrm{~h}$ and $8 \mathrm{~h})$ greater than $60 \mathrm{ppb}$ are under-estimated by the model across all the time periods as shown in Table 3. IOP 3 has the largest ozone underpredictions of all the IOPs indicated by both bias metrics, with a normalized bias that is twice the summer average. Other statistical measures do not suggest model performance for IOP 3 is inferior to the others.

In summary, the domain-wide aggregated metrics (both pattern statistics and other metrics) generally indicate similar performance between the IOPs and the whole summer with respect to predicted ozone. Next we will see that episode-to-episode differences in ozone predictions are more pronounced at a subregional level.

Figure 9 shows the spatial distribution of normalized biases in $8 \mathrm{~h}$ peak ozone (cutoff $=60 \mathrm{ppb})$ averaged over the whole summer and for individual IOPs. Large negative 
biases seen at the southern boundary sites across all the periods are due to the influence of ozone lateral boundary conditions specified at the surface ( $40 \mathrm{ppb}$ ). Flux calculations indicated that the southern boundary is dominated by outflow (Harley et al. 2006), and sensitivity studies revealed that the lateral chemical boundary conditions here have little effect on the inner parts of the domain. Model performance is most robust (normalized biases within $\pm 15 \%$ ) in the SJV across all the time periods, even during IOP1 with its less typical monsoonal flows. Larger discrepancies between modeled and observed $8 \mathrm{~h}$ ozone maxima are seen in IOPs 3 and 4 in the Sacramento Valley, Bay Area, and the Northern central coasts, where the normalized biases deviate from the summer averages. The MM5 performance evaluation indicated that the winds in the ABL exhibited less agreement during IOP3 and IOP4 in the Sacramento and central clusters (especially from the morning to the early afternoon), and this is reflected in the ozone predictions. More specifically, in IOP3, simulated winds in the Sacramento Valley are too strong in the morning and incorrectly show southerly flow in the afternoon, preventing transport of pollutants from Sacramento to the north. As a result, ozone is under-predicted in the northern part of the Sacramento Valley. At the same time stronger northwesterly components in the simulated winds enhance the removal of pollutants from the Bay Area and lead to an over-prediction of ozone in downwind areas (red coastal areas in Figure 9). In IOP4, simulated wind speeds are too high and this dilutes pollutant concentrations in the Sacramento Valley. The simulated marine flow is directed more to the south, which reduces transport of SFB emissions into the Central Valley, causing significant accumulation of ozone along the coast.

Eder et al. (2006 and 2009) found that poorer model performance generally occur under non-conducive conditions (i.e. cloud cover, precipitation, and cool temperatures). In this study, only IOP 1 occurred under a less typical Monsoonal Flow event, which has comparable model performance with summer averages. The ozone episodes IOPs 2-4 in this study are driven by high pressure systems which are characterized by high temperature and low humidity. We have seen poorest model performance in the SFB and/or SV in the episodes (IOPs 3 and 4) that are subject to the largest uncertainties in the meteorological fields. This indicates that in the central California domain, the model performance is more unique to the geographical region, where accurate simulations of 
meteorological fields are challenging even under the conducive conditions. Better seasonal model performance in the SFB and SV may suggest temporal compensating errors in these regions.

\subsubsection{Precursor predictions}

In addition to ozone, model ability to simulate a variety of ozone precursors, including $\mathrm{NO}_{\mathrm{y}}, \mathrm{CO}$, and nonmethane hydrocarbons (NMHC) is evaluated. Due to the possible titration of ozone near large $\mathrm{NO}_{\mathrm{x}}$ sources under less well mixed conditions, for $\mathrm{NO}_{\mathrm{y}}$ comparison, we only consider data in the interval from $10 \mathrm{AM}$ to $5 \mathrm{PM}$, when the atmospheric mixing is the strongest as indicated by the boundary layer heights. Modeled NMHC species are summed after being multiplied by their respective carbon numbers, and compared with observed NMHC in ppbC units.

When evaluating predictions of ozone precursors, a cutoff level corresponding to the $25^{\text {th }}$ percentile of the observed values was used; results are presented in Table 3. On average, the model underpredicts $\mathrm{NO}_{\mathrm{y}}$ concentrations during daytime hours (mean biases $-2 \sim-6 \mathrm{ppb})$. Normalized gross errors (40 50\%) suggest similar model performance throughout the summer, while other metrics suggest model performance for IOP2 is slightly less satisfactory than others. Predicted NMHC concentrations are also similar except that IOP3 has only half of the normalized error of the other periods $(60 \sim 70 \%)$ as well as a smaller normalized bias. This time period also has less than half of the number of observations compared to the other IOPs and thus is not as representative. CO concentrations are underestimated ( -30\% except IOP 3 ) by the model across all time periods considered. Predictions during IOP3 compare poorly with the observations. This IOP occurred during August, when $\mathrm{CO}$ observations tended to be rounded to the nearest 1 ppm, introducing an undesirable measurement roundoff error. In summary, these domainwide metrics do not suggest any episode is particular worse than others and precursor predictions generally have similar error and bias among the IOPs and for the whole summer.

Normalized gross errors suggest CMAQ does a better job in predicting hourly and peak ozone concentrations than in predicting ozone precursor concentrations. Such conclusions are limited by several factors such as the sparseness of available precursor 
measurements and larger incommensurability issues between model results and observations. For example, NMHC measurements are sparse both spatially and temporally, and polar oxygenated VOCs were mostly not measured, which limits representativeness of the data. In addition, VOC species in CMAQ are lumped according to functional groups and reactivities instead of carbon numbers. Aggregation of NMHC species from the model to compare with observations introduces some additional uncertainties.

The normalized biases indicate that the model underpredicts $\mathrm{NOx}$ and $\mathrm{CO}$, which are mainly emitted from mobile sources, and overpredicts VOCs, which, at the measurement locations, are mainly emitted from area sources. Errors in simulated winds and ABL depth should affect the primary species (NOx, VOC, and $\mathrm{CO}$ ) similarly as discussed in section 3.3.1. Therefore, different signs seen in prediction biases of precursor concentrations may suggest uncertainties in the emission inputs, i.e. an overestimation of area emissions, and an underestimation of motor vehicle emissions).

\section{Conclusions}

In this study we have conducted high resolution photochemical air quality modeling with MM5-CMAQ for central California over a four-month period in summer 2000. Initial diagnostic simulations were conducted on a smaller inner domain and final simulations were conducted for a larger domain after including model improvements resulting from the initial round of diagnostic simulations. We evaluated the temporal and spatial behavior of ozone predictions. We highlighted model performance in predicting ozone and its precursors in conjunction to meteorology evaluation across synopticallydriven high-ozone events (exemplified by the four IOPs), and compared them with model performance averaged over the whole summer. By doing so, we have identified features in model performance associated with simulation of different types of ozone-conducive conditions.

The time series of domain-wide aggregated performance metrics indicates that the model has stable temporal performance for the entire summer season. Hourly ozone and 1 $\mathrm{h}$ and $8 \mathrm{~h}$ peak ozone predictions of each summer day generally have normalized biases within $\pm 15 \%$ and normalized gross errors less than $25 \%$. The model on average 
underpredicts ozone (hourly or peak) levels, which is also found in previous studies (Tong and Mauzerall 2006; Eder et al. 2006 and 2009) with pair-wise comparison. Best predicted range in $8 \mathrm{~h}$ peak ozone is $60 \sim 80 \mathrm{ppb}$. Model performance varies more spatially than temporally. Ozone predictions in the SJV, where highest ozone levels are found, are consistently better than other air basins measured by various metrics. Despite the spatial differences, across all the air basins, the summer average metrics for ozone (hourly or peak) only showed modest underprediction within $10 \%$ and normalized gross errors around $20 \%$. Underprediction of $1 \mathrm{~h}$ peak ozone is associated partly with problems in peak timing in the model during the transition hours (5 - $7 \mathrm{PM})$, which are subject to more meteorological uncertainties than other times of day. $8 \mathrm{~h}$ peak ozone predictions are consistently better than the $1 \mathrm{~h}$ peak ozone.

A rich collection of field measurements enabled this study to evaluate both meteorological and chemical simulations during four synoptically-driven high ozone events. Domain-wide aggregated metrics for predicted ozone and precursor species suggest a consistent level of agreement with observations across all the IOPs, and model performance is similar to the summer average. Episode-to-episode differences in ozone predictions are more pronounced at a subregional level. Summer averages are predicted better than some of the episodes in the SFB and SV. The model exhibit the most robust performance in the SJV, and episodic ozone predictions there are similar to the summer average. This can be attributed, in part, to more accurate predictions of meteorological fields by MM5 for the SJV across all the episodes. Poorer model performance (normalized peak ozone biases $<-15 \%$ or $>15 \%$ ) is found in the Sacramento Valley and the Bay Area and is most noticeable in episodes that are subject to the largest uncertainties in meteorological fields. The Sacramento Valley exhibits poorest agreement in wind directions, which affects the northward transport of pollutants from the metropolitan areas and results in underpredictions of ozone in the northern part of the SV. The strength and direction of the simulated incoming marine flow in the San Francisco Bay Area are also subject to more uncertainties, especially during the most stagnant IOP (IOP4). Simulated ozone downwind of the SFB along the coast increases with the strength of the northwesterly component of the prevailing flow, which explains the overprediction in IOPs 3 and 4 in this region. IOPs 3 and 4 are driven by high pressure 
systems with ozone-conducive conditions (high temperature, clear skies, and stagnations, etc.). These conditions are generally found to produce satisfactory model performances (e.g. Eder et al. 2006). With a focus on high-ozone events, this study may indicate that in the central California domain, the model performance is more geographically dependent where accurate simulations of wind directions in the complex terrain of the SV and strength and timing of the onshore flow of the SFB are challenging. Currently, wind profilers deployed in the central California domain have more spatial coverage in the SJV than other air basins. More meteorological measurements are needed to improve the understanding and characterization of wind flow and other boundary layer dynamics in the SV and SFB, which can subsequently help the ozone modeling.

In addition to uncertainties seen in the meteorological fields, evaluation of ozone precursors (the model overpredicts $\mathrm{NMHC}$ and underpredicts $\mathrm{NO}_{\mathrm{y}}$ and $\mathrm{CO}$ ) suggests possible errors in the emission inventory. The agreement between predicted and measured precursor concentrations is less satisfactory than ozone, and these can be attributed, in part, to larger uncertainties in the measurements. As ozone is a secondary species, precursor observations are invaluable for evaluating photochemical modeling. To improve the understanding of precursor predictions, more real time measurements of VOC species, improved accuracy of $\mathrm{NO}_{\mathrm{y}}$ measurements, and increased spatial coverage are needed.

In regions with complex terrain, air pollution events tend to be tied to local geography. Our study shows location-specific differences in model performance under different episodic conditions, which are not revealed when performance metrics are aggregated over the whole domain. Predicted ozone levels in the Sacramento Valley, the San Francisco Bay Area, and other coastal regions can be significantly affected by uncertainties in meteorological fields, and as a result their performance metrics differ from the summer average values. Given that ozone responses to emission changes interact strongly with meteorology as shown in our sensitivity simulations, the effectiveness of emission control strategies for different episodes or time periods can differ greatly and this is a limitation of relying on episode-driven simulations for air quality planning. 


\section{Acknowledgement}

The authors would like to thank Cheryl Taylor, Klaus Scott, Neva Lowery, Bruce Jackson, and Ajith Kaduwela of the California Air Resources Board. Shaheen Tonse, Xiaoling Mao, and Claire Agnoux provided valuable assistance in data processing and model diagnostics. We thank the Technical Committee overseeing the Central California Ozone Study for helpful comments at many stages of this research. This research was supported by the Central California Air Quality Study Agency, California Energy Commission, the Assistant Secretary of Fossil Energy, Office of Natural Gas and Petroleum Technology through the National Petroleum Technology Office under the U.S. Department of Energy Contract No. DE-AC02-05CH11231. The statements and conclusions in this paper are those of the authors, and do not necessarily reflect the views of the sponsoring agencies.

\section{References}

Bell, M. L. and Dominici, F. (2008). Effect Modification by Community Characteristics on the Short-term Effects of Ozone Exposure and Mortality in 98 US Communities. Am. J. Epidemiol. 167(8): 986-997.

Bell, M. L., McDermott, A., Zeger, S. L., Samet, J. M. and Dominici, F. (2004). Ozone and Short-term Mortality in 95 US Urban Communities, 1987-2000. JAMA 292(19): 2372-2378.

Biswas, J., Hogrefe, C., Rao, S. T., Hao, W. and Sistla, G. (2001). Evaluating the performance of regional-scale photochemical modeling systems. Part III-Precursor predictions. Atmospheric Environment 35(35): 6129.

Byun, D. W. and Schere, K. L. (2006). Review of the governing equations, computational algorithms, and other components of the Models-3 Community Multiscale Air Quality (CMAQ) modeling system. Applied Mechanics Reviews 59(2): 51-77.

Carter, W. P. L. Implementation of the SARPRC-99 Chemical Mechanism into the Model-3 Framework. University of California, Riverside, California, Washington, D. C. 2000.

Coats, C. J. High Performance Algorithms in the Sparse Matrix Operator Kernel Emissions (SMOKE) Modeling System, Microelectrics Center of North Carolina, Environmental Systems Division, Research Triangle Park, NC. 1995

Eder, B., Kang, D., Mathur, R., Yu, S. and Schere, K. (2006). An operational evaluation of the Eta-CMAQ air quality forecast model. Atmospheric Environment 40(26): 4894. 
Emberson, L. D., Bder, P., Ashmore, M. R., Mills, G., Jackson, L. S., Agrawal, M., Atikuzzaman, M. D., Cinderby, S., Engardt, M., Jamir, C., Kobayashi, K., Oanh, N. T. K., Quadir, Q. F. and Wahid, A. (2009). A comparison of North American and Asian exposure-response data for ozone effects on crop yields. Atmospheric Environment 43(12): 1945.

Fujita, E., D. Campbell, R. Keisler, J. Brown, S. Tanrikulu, and A. J. Ranzieri, (2001). Central California Ozone Study (CCOS) - Final report,Volume III: Summary of field operations. Technical report, California Air Resources Board,

Grell, G. A., (1993). Prognostic evaluation of assumptions used by cumulus parameterizations. Mon. Wea. Rev., 121, 764-787.

Grell, G. A., Dudhia, J. and Stauffer, D. R. A description of the fifth-generation Penn State/NCAR mesoscale model (MM5). NCAR Technical Note, NCAR/TN398+STR, 122 pp., NCAR, Boulder, CO, 1994

Guenther, A., Hewitt, C. N., Erickson, D., Fall, R., Geron, C., Graedel, T., Harley, P., Klinger, L., Lerdau, M., McKay, W. A., Pierce, T., Scholes, B., Steinbrecher, R., Tallamraju, R., Taylor, J. and Zimmerman, P. (1995). A Global-Model Of Natural Volatile Organic-Compound Emissions. Journal of Geophysical ResearchAtmospheres 100(D5): 8873-8892.

Harley, R.A., N.J. Brown, S.R. Tonse, L. Jin, A seasonal perspective on regional air quality in central California. Department of Civil and Environmental Engineering, UC Berkeley and Atmospheric Science Department, Lawrence Berkeley National Laboratory, Berkeley, CA. Phase I final report for San Joaquin Valley wide Air Pollution Study Agency and the California Air Resources Board. 2006.

Hogrefe, C., Biswas, J., Lynn, B., Civerolo, K., Ku, J. Y., Rosenthal, J., Rosenzweig, C., Goldberg, R. and Kinney, P. L. (2004a). Simulating regional-scale ozone climatology over the eastern United States: model evaluation results. Atmospheric Environment 38(17): 2627.

Hogrefe, C., Lynn, B., Civerolo, K., Ku, J.-Y., Rosenthal, J., Rosenzweig, C., Goldberg, R., Gaffin, S., Knowlton, K. and Kinney, P. L. (2004b). Simulating changes in regional air pollution over the eastern United States due to changes in global and regional climate and emissions. J. Geophys. Res., 109, D22301, doi:10.1029/2004JD004690.

Hogrefe, C., Porter, P. S., Gego, E., Gilliland, A., Gilliam, R., Swall, J., Irwin, J. and Rao, S. T. (2006). Temporal features in observed and simulated meteorology and air quality over the Eastern United States. Atmospheric Environment 40(26): 5041.

Hogrefe, C., Rao, S. T., Kasibhatla, P., Hao, W., Sistla, G., Mathur, R. and McHenry, J. (2001). Evaluating the performance of regional-scale photochemical modeling systems: Part II--ozone predictions. Atmospheric Environment 35(24): 4175.

IPCC (2007), Climate Change 2007: The Physical Science Basis-Contribution of Working Group I to the Fourth Assessment Report of the Intergovernmental Panel on Climate Change, edited by S. Solomon et al., Cambridge Univ. Press, Cambridge, U. K. 
Janjić, Z. I., 2002: Nonsingular Implementation of the Mellor-Yamada Level 2.5 Scheme in the NCEP Meso model, NCEP Office Note, No. 437, 61 pp.

Jin, L., Brown, N., Tonse, S., Harley, R., Bao, J., Michelson, S. and Wilczak, J. (2007). Diagnostic and mechanistic evaluation of MM5-CMAQ for the summer 2000 central California ozone study. the 6th Annual CMAS Conference, Oct. 1-3, Chapel Hill, NC.

Jin, L., Tonse, S., Cohan, D. S., Mao, X., Harley, R. A. and Brown, N. J. (2008). Sensitivity Analysis of Ozone Formation and Transport for a Central California Air Pollution Episode. Environ. Sci. Technol. 42(10): 3683-3689.

Liao, H., Chen, W.-T. and Seinfeld, J. H. (2006). Role of climate change in global predictions of future tropospheric ozone and aerosols. J. Geophys. Res. 111 D12304, doi:10.1029/2005JD006852.

Lippmann, M. (1989). Health effects of ozone. A critical review. JAPCA 39(5): 672-695.

Lippmann, M. (1993). Health effects of tropospheric ozone: review of recent research findings and their implications to ambient air quality standards. $J$ Expo Anal Environ Epidemiol 3(1): 103-29.

Mebust, M. R., Eder, B. K., Binkowski, F. S. and Roselle, S. J. (2003). Models-3 Community Multiscale Air Quality (CMAQ) model aerosol component 2. Model evaluation. J. Geophys. Res. 108 doi:10.1029/2001JD001410.

Michelson, S. A., I. V. Djalalova, and J.-W. Bao, 2009: Evaluation of the summertime low-level winds simulated by MM5 in the Central Valley of California. Submitted to J. of Appl. Meteor. Clim.

Nolte, C. G., Gilliland, A. B., Hogrefe, C. and Mickley, L. J. (2008). Linking global to regional models to assess future climate impacts on surface ozone levels in the United States. J. Geophys. Res. 113, D14307, doi:10.1029/2007JD008497.

Russell, A. and Dennis, R. (2000). NARSTO critical review of photochemical models and modeling. Atmospheric Environment 34(12-14): 2283.

Scott, K. I. and Benjamin, M. T. (2003). Development of a biogenic volatile organic compounds emission inventory for the SCOS97-NARSTO domain. Atmospheric Environment 37(Supplement 2): 39-49.

Stein, M.L., 1999. Interpolation of Spatial Data. Some Theory for Kriging. Springer, New York, 247pp.

Steiner, A. L., S. Tonse, R. C. Cohen, A. H. Goldstein, R. A. Harley (2006). Influence of future climate and emissions on regional air quality in California. J. Geophys. Res. 111: D18303, doi:10.1029/2005JD006935.

Stevenson, D. S., Johnson, C. E., Collins, W. J., Derwent, R. G. and Edwards, J. M. (2000). Future estimates of tropospheric ozone radiative forcing and methane turnover - the impact of climate change. Geophysical Research Letters 27(14): 2073-2076. 
Swall, J. L. and Foley, K. M. (2009). The impact of spatial correlation and incommensurability on model evaluation. Atmospheric Environment 43(6): 1204.

Tao, Z., Williams, A., Huang, H.-C., Caughey, M. and Liang, X.-Z. (2007). Sensitivity of U.S. surface ozone to future emissions and climate changes. Geophys. Res. Lett. 34.

Taylor, K. E. (2001). Summarizing multiple aspects of model performance in a single diagram. J. Geophys. Res. 106(D7): 7183-7192.

Tong, D. Q. and Mauzerall, D. L. (2006). Spatial variability of summertime tropospheric ozone over the continental United States: Implications of an evaluation of the CMAQ model. Atmospheric Environment 40(17): 3041.

Vautard, R., Builtjes, P. H. J., Thunis, P., Cuvelier, C., Bedogni, M., Bessagnet, B., Honor, C., Moussiopoulos, N., Pirovano, G., Schaap, M., Stern, R., Tarrason, L. and Wind, P. (2007). Evaluation and intercomparison of Ozone and PM10 simulations by several chemistry transport models over four European cities within the CityDelta project. Atmospheric Environment 41(1): 173.

Winner, D. A. and Cass, G. R. (2000). Effect of Emissions Control on the Long-Term Frequency Distribution of Regional Ozone Concentrations. Environ. Sci. Technol. 34(12): 2612-2617.

Zhang, M., Uno, I., Zhang, R., Han, Z., Wang, Z. and Pu, Y. (2006). Evaluation of the Models-3 Community Multi-scale Air Quality (CMAQ) modeling system with observations obtained during the TRACE-P experiment: Comparison of ozone and its related species. Atmospheric Environment 40(26): 4874.

Zhang, Y., Vijayaraghavan, K. and Seigneur, C. (2005). Evaluation of three probing techniques in a three-dimensional air quality model. J. Geophys. Res. 110: D02305, doi:10.1029/2004JD005248.

US Environmental Protection Agency (US EPA) (1991). Guidance for regulatory application of the Urban Airshed Model. EPA450/4-91-013, July 1991, United States Environmental Protection Agency, Research Triangle Park, NC 27711. 
Table 1 Summary of initial model diagnostic simulations

\begin{tabular}{|c|c|c|c|}
\hline No. & $\begin{array}{l}\text { Simulation } \\
\text { Purpose }\end{array}$ & Process or Parameter Investigation & $\begin{array}{l}\text { Affected Species / Geographic } \\
\text { Areas }\end{array}$ \\
\hline 1 & $\begin{array}{l}\mathrm{O}_{3} \text { sensitivity to } \\
\mathrm{BC}\end{array}$ & $\begin{array}{l}\text { Ozone sensitivity calculated by } \\
\text { decoupled direct method (DDM) to } \\
\text { boundary ozone, and its precursors (NO, } \\
\mathrm{NO}_{2} \text {, and VOC). Brute force } \\
\text { perturbation at different vertical layers. }\end{array}$ & $\begin{array}{l}\text { Simulated ozone is most } \\
\text { sensitive to boundary ozone. } \\
\text { Coastal sites are most affected. } \\
\text { Upper layer (above } 3 \mathrm{~km} \text { ) } \mathrm{O}_{3} \\
\text { boundary condition values do } \\
\text { not exert a significant influence } \\
\text { on surface values anywhere in } \\
\text { the modeling domain. }\end{array}$ \\
\hline 2 & $\begin{array}{l}\text { Constant ozone } \\
\text { BC vs Vertically } \\
\text { Varying ozone } \\
\text { BC }\end{array}$ & $\begin{array}{l}\text { Change constant ozone boundary ( } 40 \mathrm{ppb} \\
\text { at all layers) to a vertically varying } \\
\text { profile (20ppb at bottom, and increasing } \\
\text { aloft) derived from Trinidad head } \\
\text { measurements. }\end{array}$ & $\begin{array}{l}\text { Using the vertically varying } \\
\text { ozone boundary decreases } \\
\text { modeled coastal ozone, and } \\
\text { increases inland ozone, by } \\
\sim 5 \mathrm{ppb} \text {. }\end{array}$ \\
\hline 3 & $\begin{array}{l}\text { Minimum eddy } \\
\text { diffusivity } \\
\mathrm{K}_{\text {zmin }}\end{array}$ & $\begin{array}{l}\text { Change the default value of minimal } \\
\text { vertical eddy diffusivity used in CMAQ } \\
\text { from } 0.5 \text { to } 0.1 \mathrm{~m}^{2} \mathrm{~s}^{-1} \text { based on } \\
\text { Jacobson (1999). }\end{array}$ & $\begin{array}{l}\text { Lowered nighttime and some } \\
\text { daytime morning } \mathrm{O}_{3} \text { of the } \\
\text { inland areas by } \sim 10 \mathrm{ppb} \text {. Both } \\
\text { day- and night-time coastal } \\
\text { ozone are affected. }\end{array}$ \\
\hline 4 & $\begin{array}{l}\text { Ozone dry } \\
\text { deposition rate } \\
\mathrm{V}_{\mathrm{d} \_\mathrm{O} 3}\end{array}$ & $\begin{array}{l}\text { Brute force sensitivity conducted by } \\
\text { adding } 0.05 \mathrm{~cm} / \mathrm{s}, 0.1 \mathrm{~cm} / \mathrm{s} \text {, and } 0.5 \mathrm{~cm} / \mathrm{s} \\
\text { to the default ozone dry deposition rate } \\
\text { in MM5 input file. Change the zero } \\
\text { ozone dry deposition rate to } 0.04 \mathrm{~cm} / \mathrm{s} \\
\text { based on Wesley (2000) and } \\
\text { measurements by Faloona }(2006) \text {. }\end{array}$ & $\begin{array}{l}\text { Nighttime ozone and ozone at } \\
\text { coastal sites are most sensitive to } \\
\text { ozone dry deposition rate. }\end{array}$ \\
\hline 5 & $\begin{array}{l}\text { Nighttime } \\
\text { titration effects }\end{array}$ & $\begin{array}{l}\text { Compare simulated } \mathrm{NO}_{2}+\mathrm{O}_{3} \text { to } \\
\text { observed values. }\end{array}$ & $\begin{array}{l}\text { Sites near road ways affected the } \\
\text { most, where } \\
\mathrm{NO}+\mathrm{O}_{3} \rightarrow \mathrm{NO}_{2}+\mathrm{O}_{2} \text { occurs. } \\
\text { Improved agreement during } \\
\text { nighttime. }\end{array}$ \\
\hline 6 & $\begin{array}{l}\text { Nudged vs } \\
\text { unnudged winds } \\
\text { on pollutant } \\
\text { predictions }\end{array}$ & $\begin{array}{l}\text { Compared performances simulated } \\
\text { under the nudged and unnudged } \\
\text { meteorological inputs, respectively. }\end{array}$ & $\begin{array}{l}\text { Better comparison (especially in } \\
\text { the Bay Area and Sacramento } \\
\text { Valley) in ozone is seen during } \\
\text { the day where nudged winds } \\
\text { showed the most improvement } \\
\text { relative to the unnudged winds. } \\
\text { Overall performance is similar } \\
\text { in the two cases. }\end{array}$ \\
\hline 7 & $\begin{array}{l}\text { Ozone } \\
\text { sensitivity to } \\
\text { emission } \\
\text { uncertainties }\end{array}$ & $\begin{array}{l}\text { First- and second-order sensitivity } \\
\text { coefficients computed using Higher- } \\
\text { order Decoupled Direct Method } \\
\text { (HDDM). }\end{array}$ & $\begin{array}{l}\text { SJV Ozone is mostly sensitive to } \\
\text { its local emissions, except the } \\
\text { very northern part of the valley, } \\
\text { which is affected by the SFB } \\
\text { emissions. Ozone sensitivities } \\
\text { are mostly influenced by } \\
\text { uncertainties in emissions and } \\
\text { the termination reaction }\left(\mathrm{NO}_{2}\right. \\
\left.+\mathrm{OH} \rightarrow \mathrm{HNO}_{3}\right) \text { rate coefficient. }\end{array}$ \\
\hline
\end{tabular}




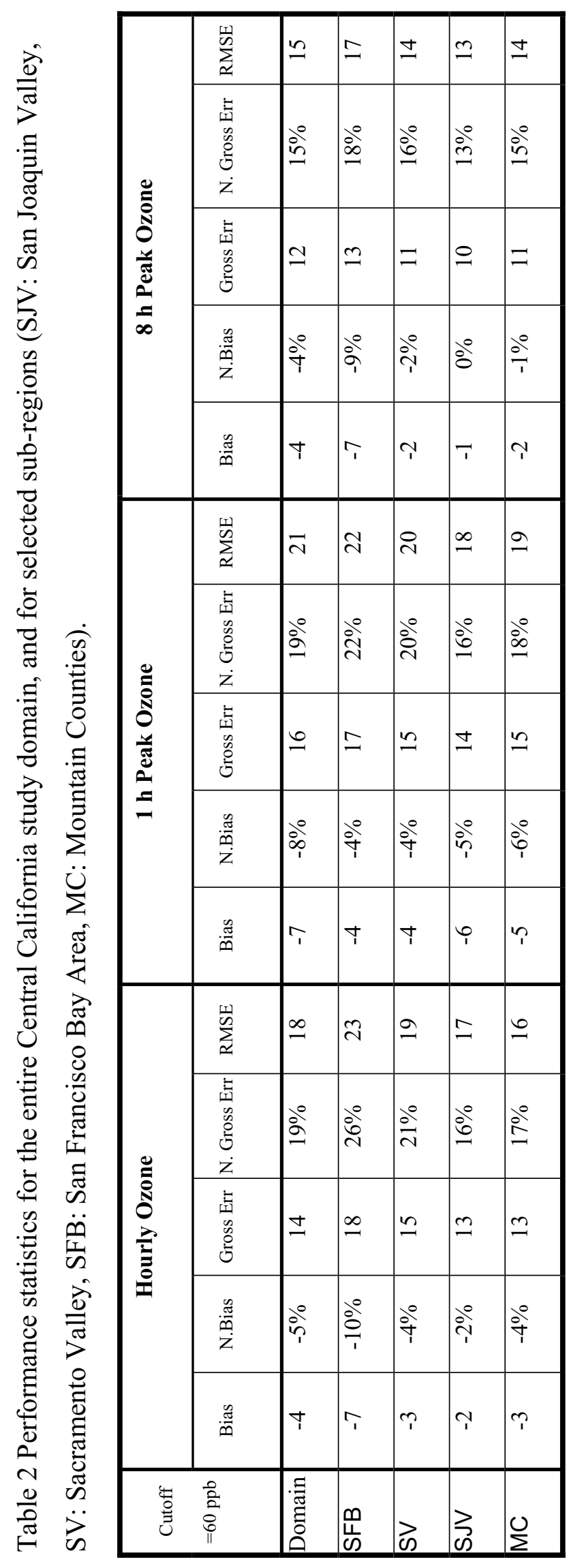




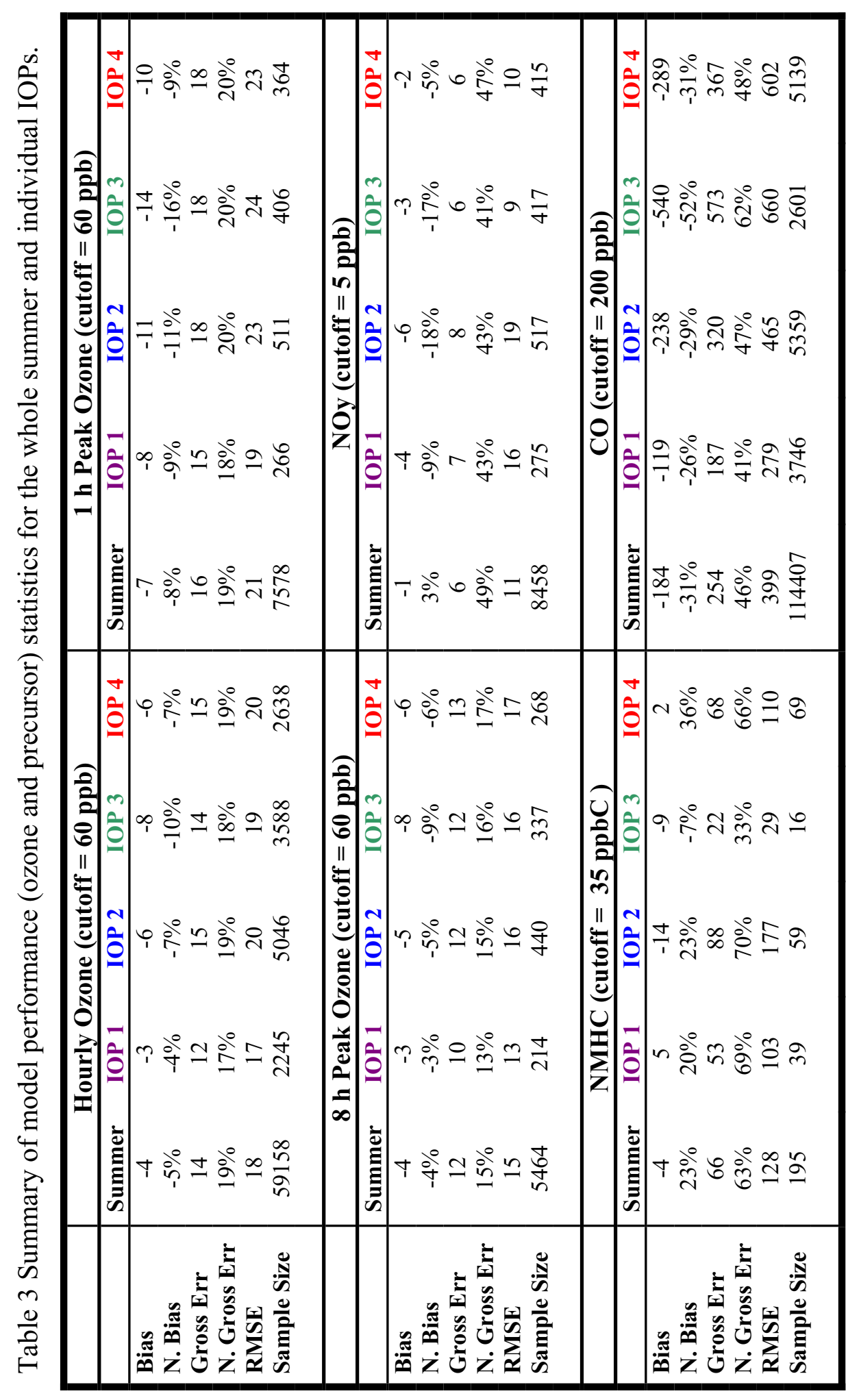




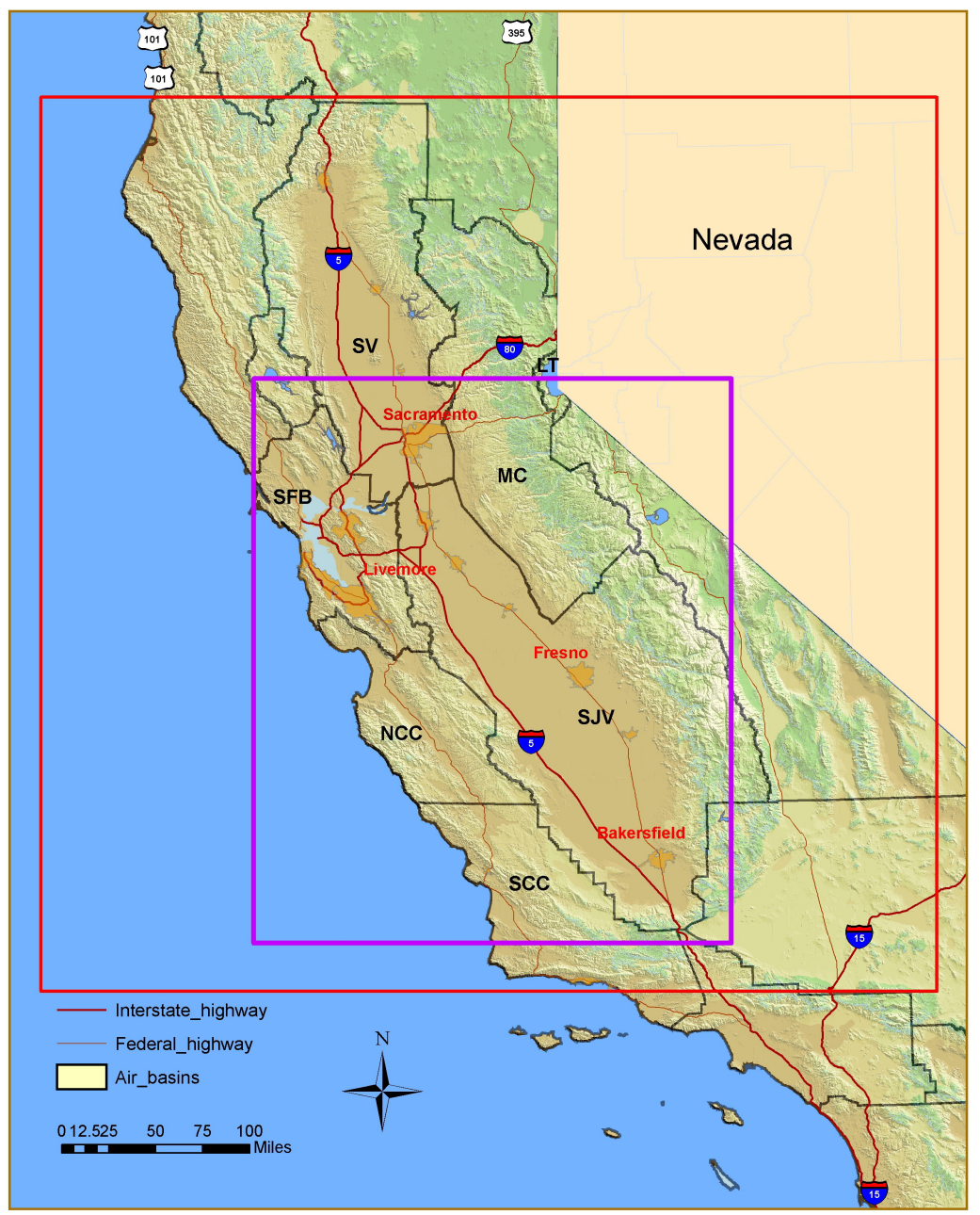

Figure 1 CCOS domain shown in the outer red rectangle, a grid of $185 \times 185$ with each cell having a resolution of $4 \mathrm{~km} \times 4 \mathrm{~km}$. The inner purple rectangle shows the previous SARMAP doamin, a 96 by 117 grid. Major air basins labeled on the map are: San Joaquin Valley (SJV), Sacramento Valley (SV), San Francisco Bay Area (SFB), Mountain Counties (MC), North Central and South Central Coasts (NCC and SCC). 


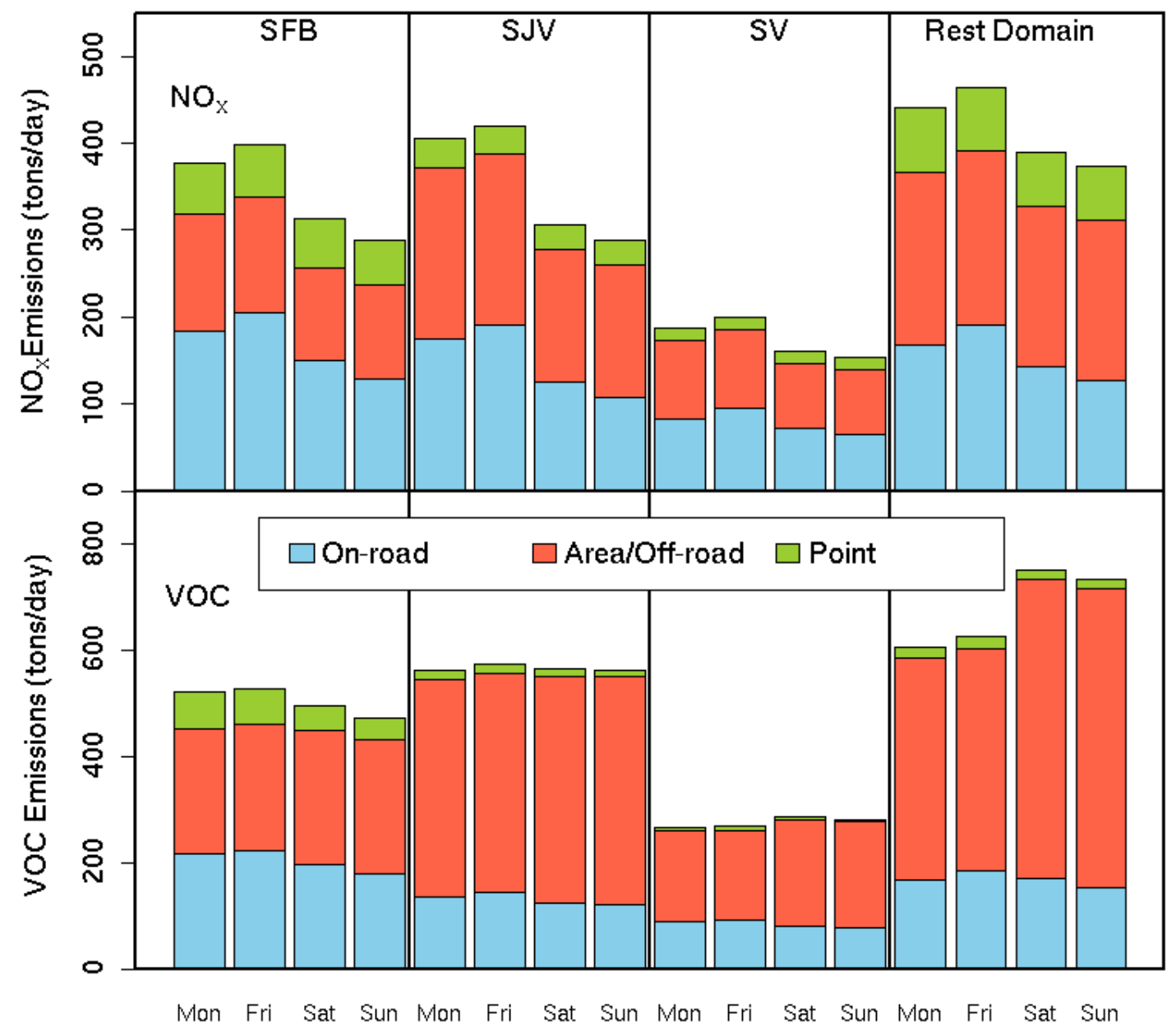

Figure 2 Daily total emissions in summer 2000 from anthropogenic sources for selected subregions. Monday emissions were applied as well to other weekdays, Tuesday through Thursday. 


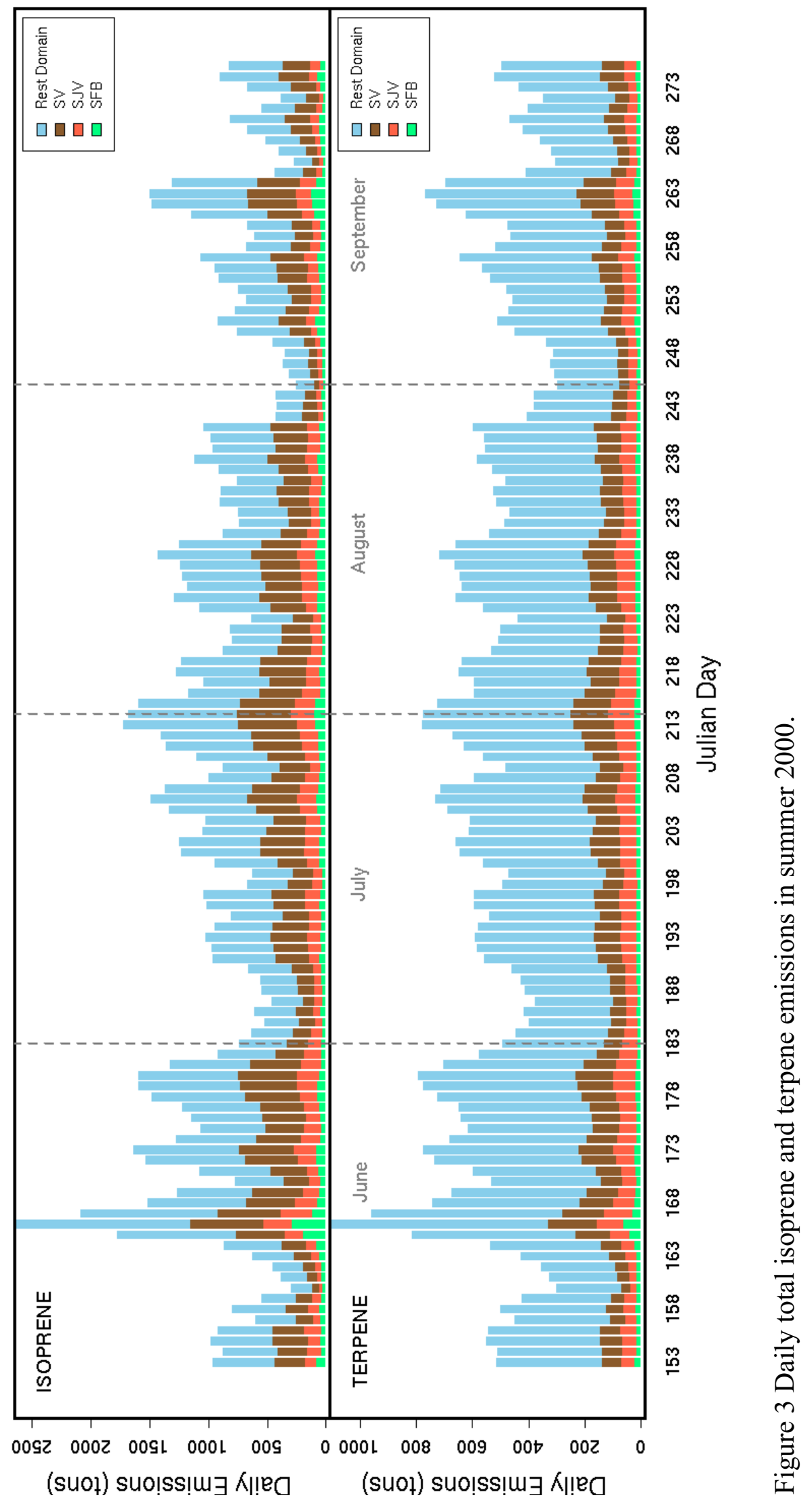



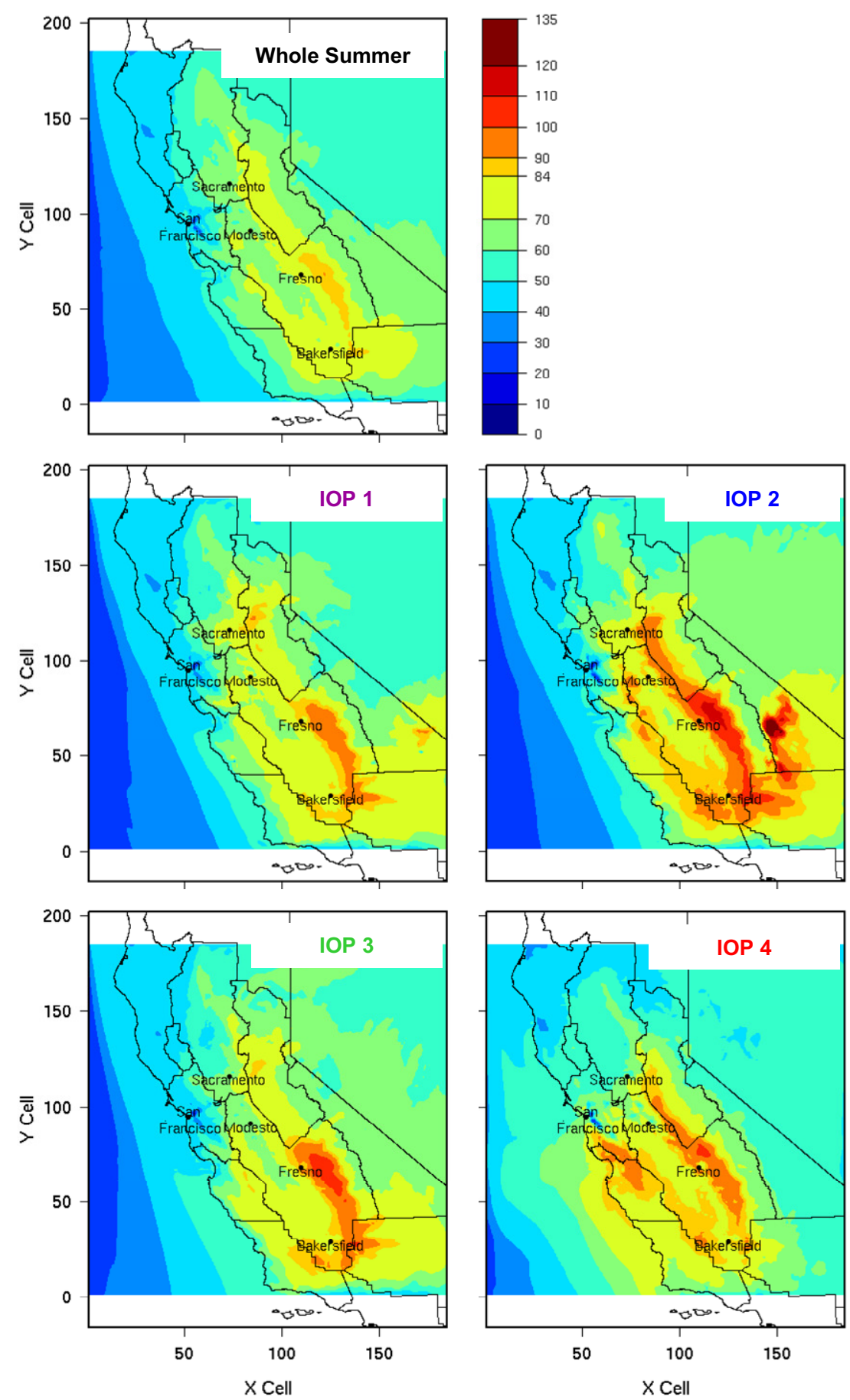

Figure 4 Simulated $8 \mathrm{~h}$ peak ozone (ppb) averaged over the whole summer and individual Intensive Operating Periods (IOPs). 

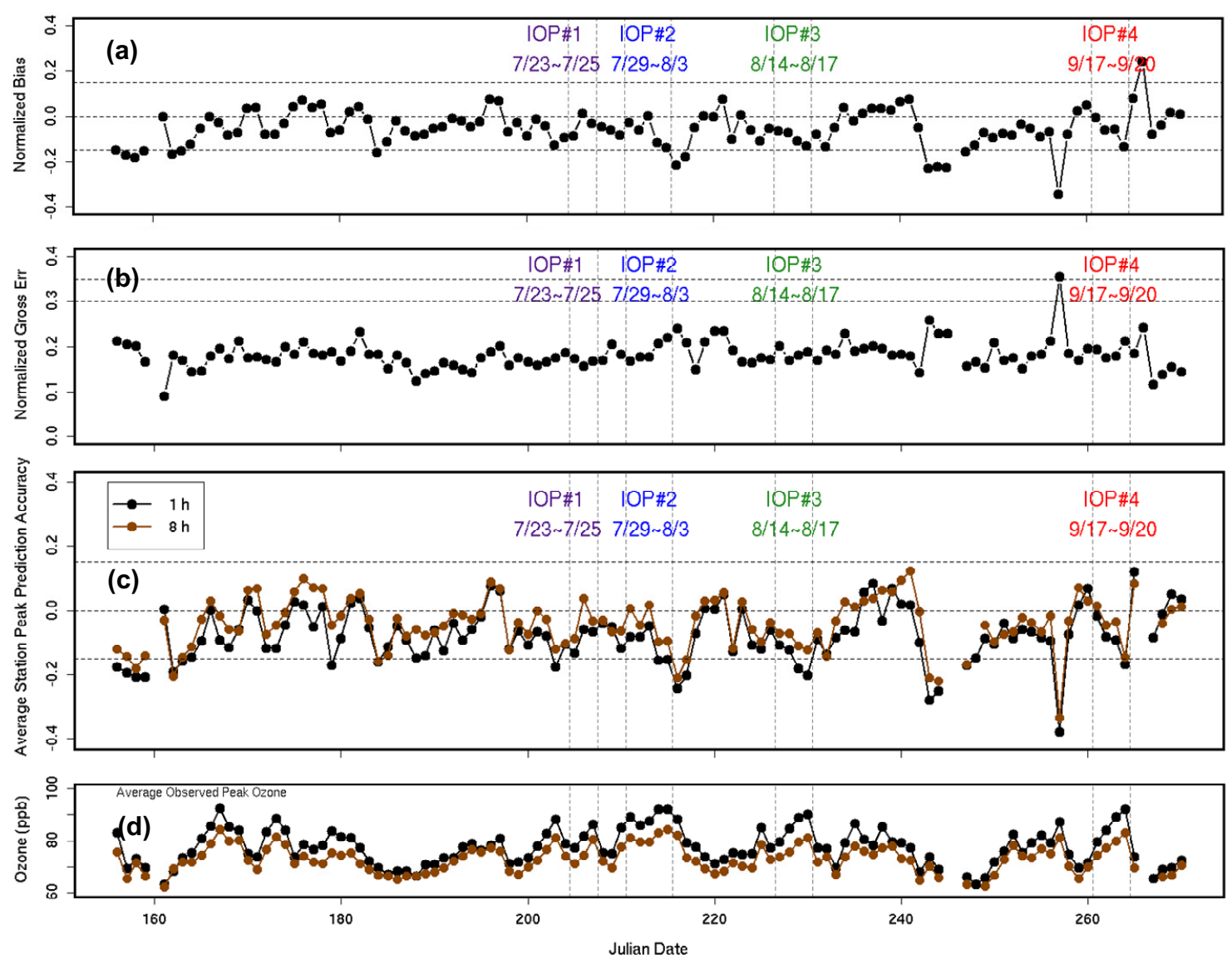

Figure 5 (a) Daily normalized biases and (b) normalized gross errors of hourly ozone with cutoff $=60 \mathrm{ppb}$; (c) daily average station peak prediction accuracy (for $1 \mathrm{~h}$ and $8 \mathrm{~h}$ peak ozone), along with (d) daily average observed peak ozone levsels. Horizontal dashed lines denote EPA guidance for acceptable model performance (normalized bias within $\pm 15 \%$, and normalized gross error less than $30-35 \%$ ). 


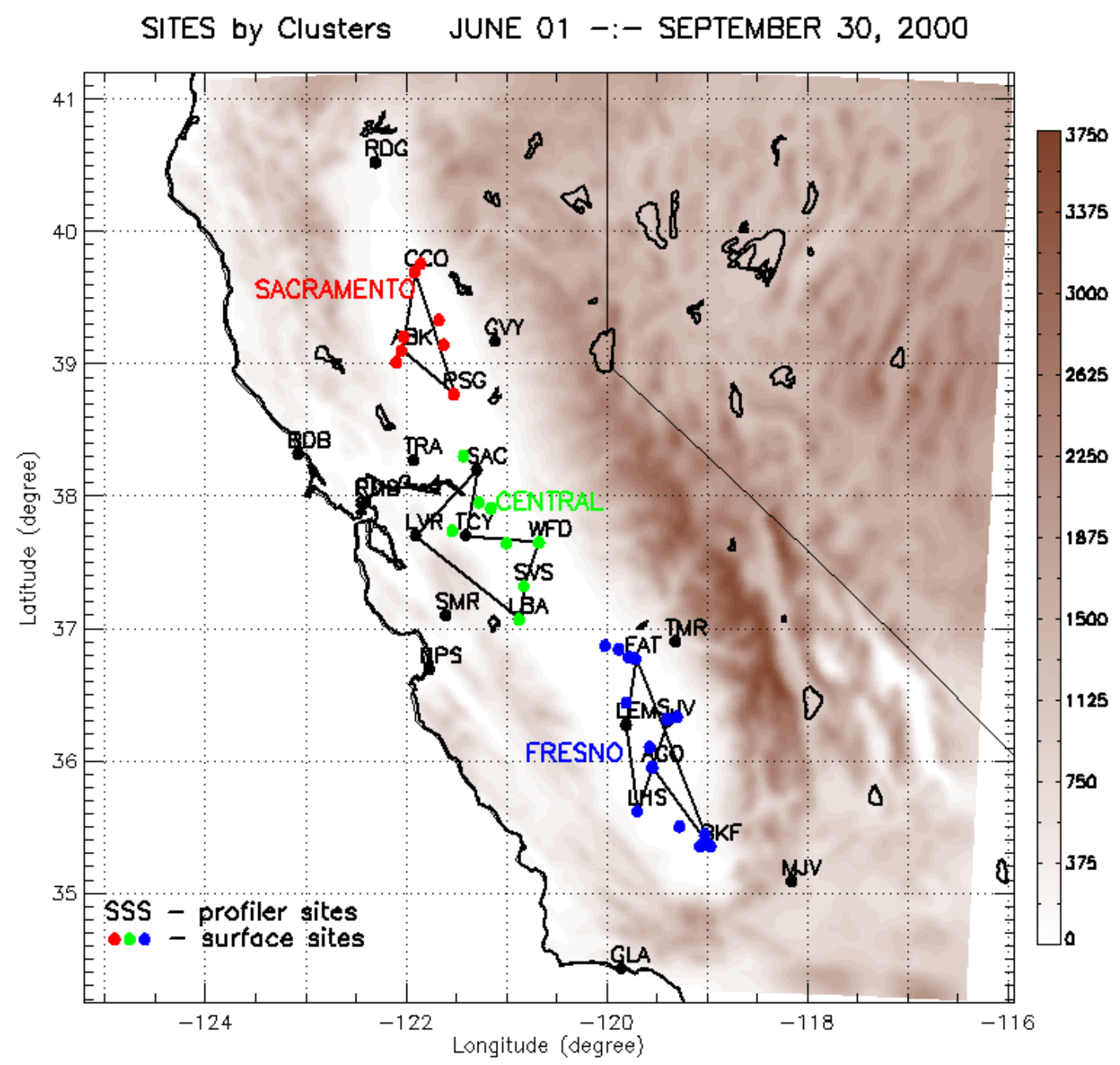

Figure 6 Location of wind profiler clusters used for MM5 model evaluation. The Sacramento cluster is shown in red, the central cluster in green, and the Fresno cluster in blue. 

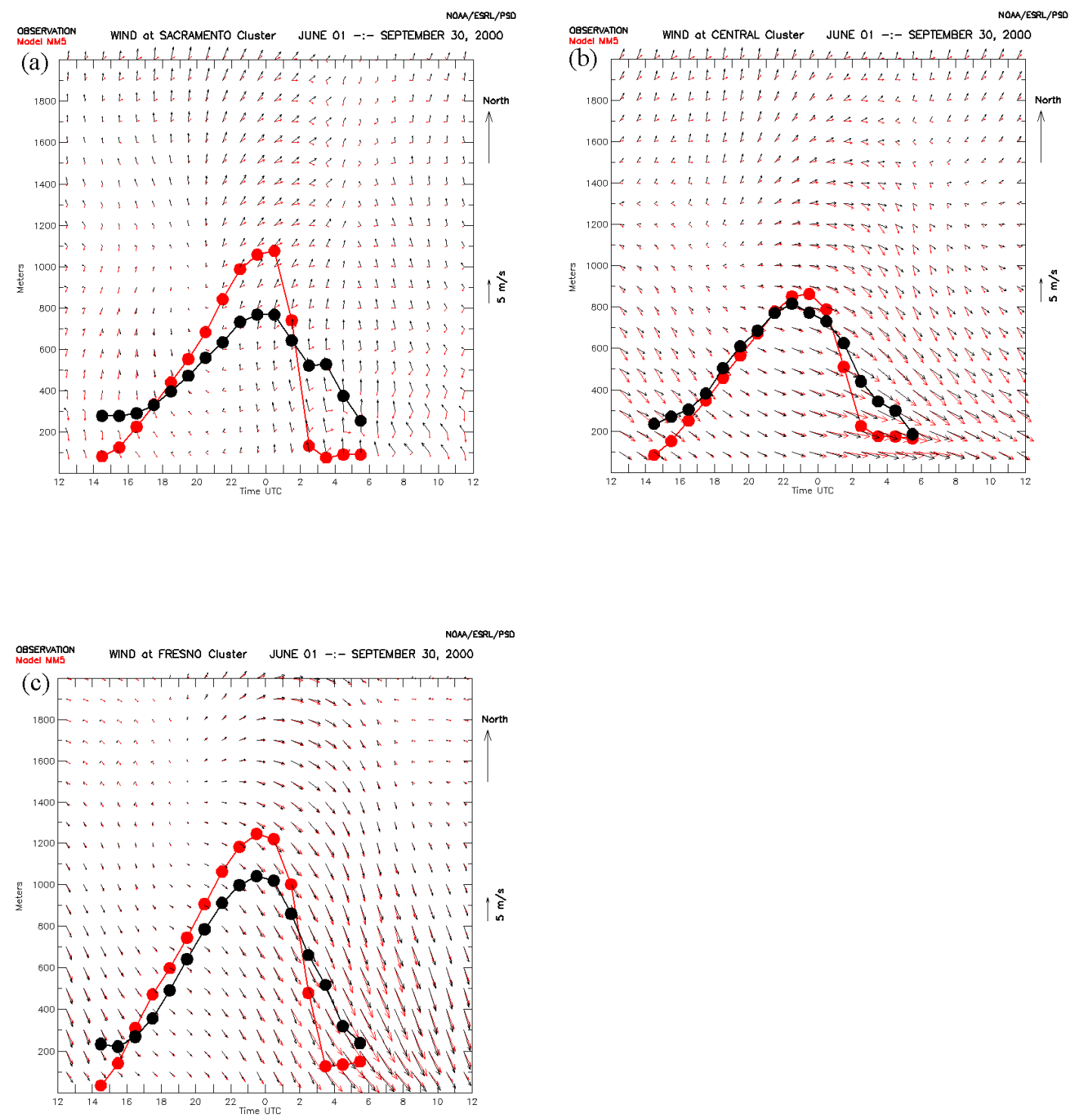

Figure 7 Time-height series of the MM5-simulated (red vectors) and observed (black vectors) wind along with the MM5-simulated (red dots) and observed (black dots) atmospheric boundary layer depth averaged over entire summer (1 June-30 September 2000). 


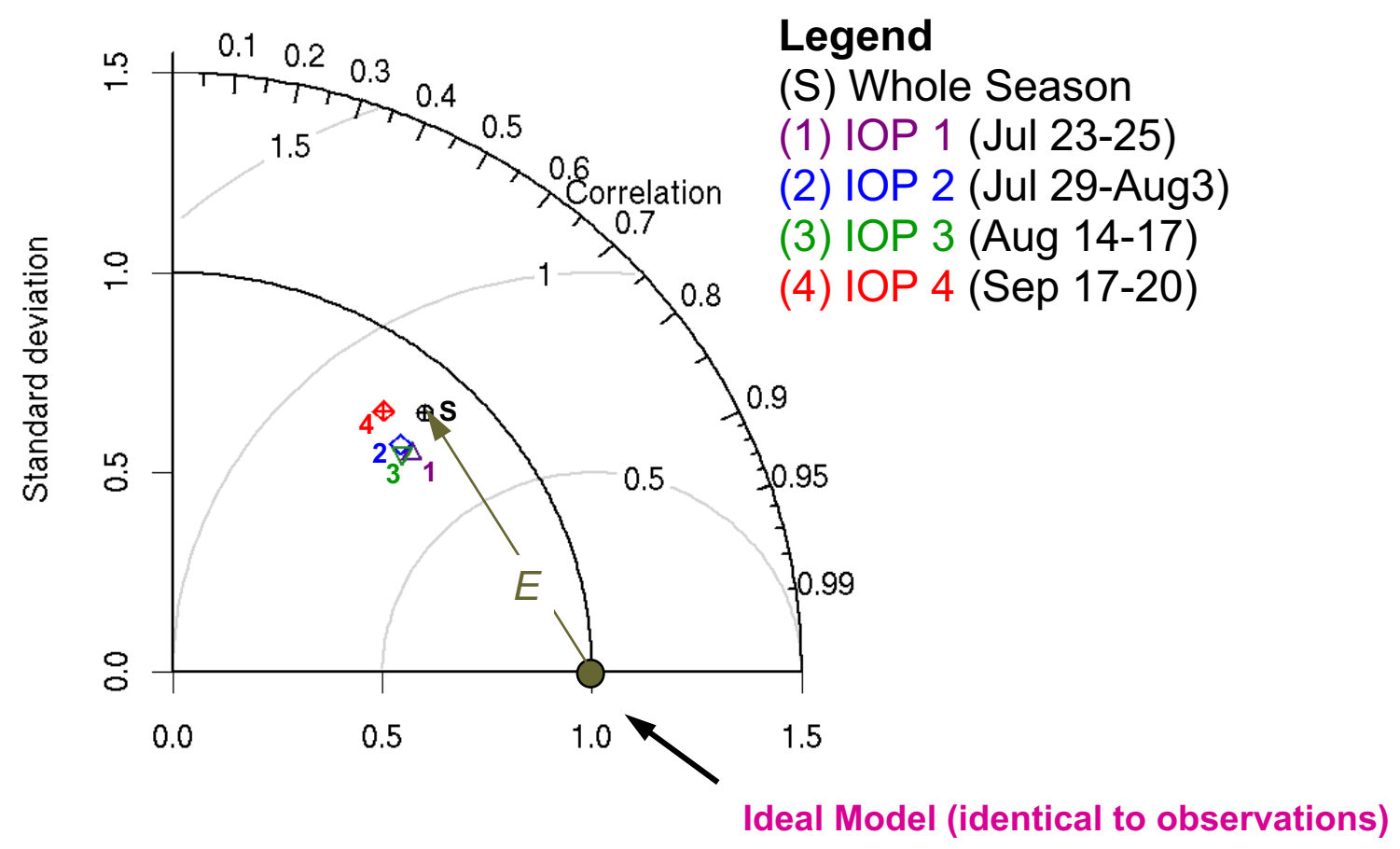

Figure 8 Taylor diagram indicates three pattern statistics: standard deviation, root mean squared difference (E indicated on the diagram), and correlation between the modeled and observed daytime ozone for the whole summer season and individual intensive operating periods. Standard deviation and root mean squared difference are normalized using the standard deviation of the observations. 

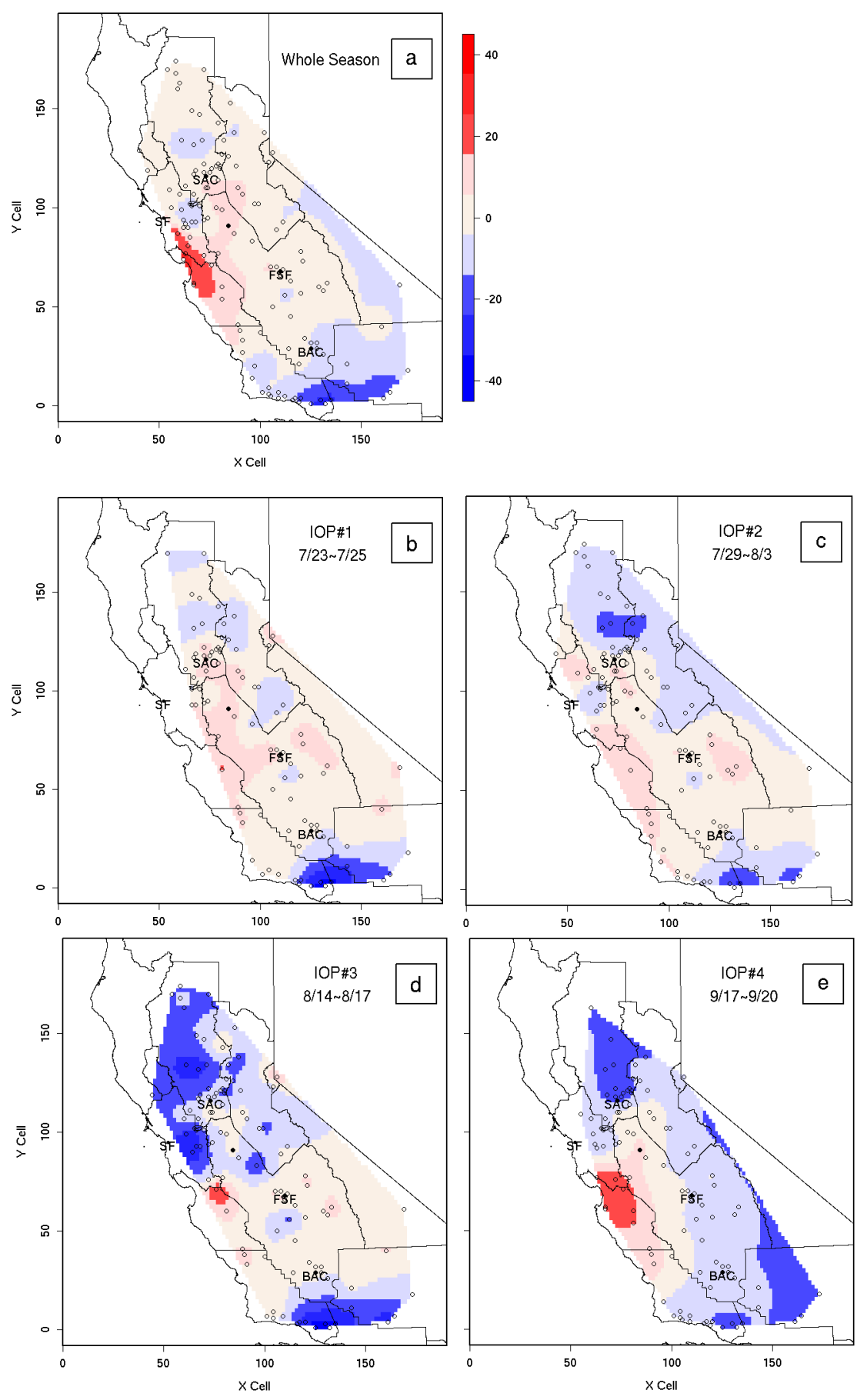

Figure 9 Normalized bias (\%) surface of $8 \mathrm{~h}$ peak ozone predictions for the whole summer (a) and individual IOPs (b-e). Biases are kriged into a continuous surface with the Matern function (Stein 1999) in R. Dots indicate surface observation sites. Major cities are labeled on the plots: SF - San Francisco, SAC - Sacramento, FSF - Fresno, and BAC - Bakersfield. 